\title{
Meningiomas: the role of preoperative angiography and embolization
}

\author{
Christopher F. Dowd, M.D., Van V. Halbach, M.D., and Randall T. Higashida, M.D. \\ The Neurovascular Medical Group, University of California San Francisco School of Medicine, San \\ Francisco, California
}

\begin{abstract}
The field of interventional neuroradiology has experienced remarkable technological developments in microcatheters and embolic materials during the past two decades. The realm of meningioma therapy has benefited handsomely from the combination of these technical improvements and the knowledge of experienced practitioners in this field. Transarterial embolization has become a standard procedure in the preoperative management of meningiomas. The authors describe the indications, pretreatment evaluation, techniques, and outcomes when preoperative angiography and embolization are performed in the treatment of these tumors.
\end{abstract}

KeY WORDS • meningioma • embolization • angiography • brain tumor

Meningiomas are extraaxial brain tumors derived from arachnoid cells of neural crest origin. They are found along the dural lining of the venous sinuses of the brain and skull base, locations where arachnoid cells are most plentiful. Thus, meningiomas are commonly found at the cerebral convexity, petrous ridge, sphenoid wing, tentorium, foramen magnum, cerebellopontine angle, and cavernous sinus. They comprise $20 \%$ of primary intracranial tumors and are identified more commonly in older patients and in women. ${ }^{18}$ Presenting signs and symptoms depend on the lesion's size and location and include headache, seizure, and neurological deficit due to local mass effect. With ever-increasing use of cross-sectional brain imaging, smaller, incidental meningiomas may be discovered during imaging evaluation for unrelated symptoms.

During the past several decades, there have been rapid technological developments in microcatheters and embolic materials in the realm of interventional neuroradiology. ${ }^{2}$ Combined with experience, these improvements have permitted the adoption of safe and effective embolization techniques for the preoperative treatment of meningiomas, allowing simpler resection. In this paper we will outline

Abbreviations used in this paper: $\mathrm{CT}=$ computerized tomography; ECA = external carotid artery; ICA = internal carotid artery; MMA = middle meningeal artery MR = magnetic resonance; $\mathrm{VA}=$ vertebral artery. the principles involved in performing preoperative angiography and embolization for meningiomas.

\section{ROLE OF PREOPERATIVE ANGIOGRAPHY AND EMBOLIZATION}

\section{Pretreatment Imaging Evaluation}

Initial imaging evaluation often involves obtaining a CT scan. Noncontrast CT scanning classically demonstrates a dural-based, homogeneous tumor of increased density compared with surrounding brain, with variable mass effect and surrounding edema. Hyperostosis of adjacent bone is a common feature of the meningioma. Contrast administration produces dramatic homogeneous enhancement of the tumor and often reveals a dural tumor tail.

With its multiplanar capabilities, MR imaging provides additional information and good soft-tissue differentiation. On $\mathrm{T}_{1}$-weighted MR images, the tumor is of equivalent signal intensity compared with surrounding brain, and $\mathrm{T}_{2}$-weighted MR imaging reveals that the tumor signal is slightly increased compared with normal brain, but less so than that of cerebrospinal fluid. Fluid-attenuated inversion recovery MR imaging highlights surrounding edema. With administration of Gd, MR imaging demonstrates homogeneous tumor enhancement. Absence of flow signal in an adjacent dural sinus may indicate that tumor invasion and occlusion of the sinus have occurred. 
C. F. Dowd, V. V. Halbach, and R. T. Higashida

Neuroimaging findings suggestive of atypical meningioma include tumor inhomogeneity (either before or after contrast administration), tumor margin irregularity, rapid interval growth, abundant surrounding edema, and markedly enlarged internal tumor vessels. Such features should prompt consideration of other, less common diagnoses such as hemangiopericytoma or angiosarcoma.

\section{Angiographic Evaluation}

Angiography is not generally indicated unless embolization is planned. The classic angiographic appearance of a meningioma is that of increasing hypervascular tumor blush throughout the arterial phase, persisting well into the late venous phase with slow washout. Meningiomas are commonly supplied by dural arteries, which normally supply the covering of the brain. Such arteries include the MMA, accessory meningeal, ascending pharyngeal, or occipital transmastoid perforating branches of the ECA (depending on the location of the tumor). Dural arteries also include the tentorial and inferolateral trunk branches of the ICA, as well as the posterior meningeal branch of the VA. Secondary supply to a meningioma may be derived from pial branches (branches of the anterior, middle, and posterior cerebral arteries that supply the brain substance itself). Diagnostic angiography can also identify important information for the surgeon such as potential occlusion of a dural sinus adjacent to the tumor and the pattern of collateral venous drainage around such an occlusion.

\section{Embolization Technique}

The optimal treatment for meningiomas is complete resection, when possible. Factors that can hinder extirpation include tumor hypervascularity (which can complicate and lengthen the operation), encasement of major arteries or cranial nerves, and tumor involvement of a dural venous sinus. Embolization involves the devascularization of a tumor's blood supply through the placement of an embolic agent via a microcatheter into the feeding arteries. Because meningiomas are usually quite vascular, preoperative embolization (Figs. 1 and 2) can ease complete tumor resection by diminishing operative time and intraoperative blood loss. ${ }^{8,12}$ After a diagnostic arteriogram is obtained to identify blood supply and to assess safety and feasibility of embolization, a microcatheter (a small-lumen, flexible catheter) is navigated through the larger diagnostic angiography catheter and is directed over a microguidewire to the artery supplying the tumor. Real-time digital-subtraction fluoroscopy (so-called "road-mapping" technology) is essential for this maneuver. Superselective angiography is performed through the microcatheter to confirm its proper position and to identify any normal branches that might preclude safe embolization. ${ }^{15}$ The following must be identified and examined to avoid potentially disastrous complications: the distal internal maxillary artery (potential communication with the ICA), the neuromeningeal trunk of the ascending pharyngeal artery (supply to ninth, 10th and 11th cranial nerves), the odontoid branch of the ascending pharyngeal artery (potential VA anastomosis), and the meningolacrimal branch of the MMA (potential retinal supply). Provocative

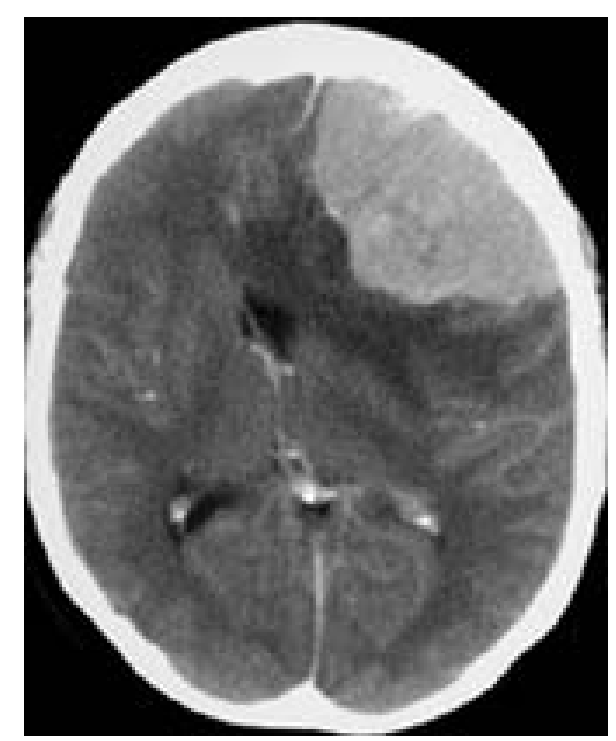

Fig. 1. Contrast-enhanced axial CT scan obtained in a 59-yearold woman, revealing a well-circumscribed homogeneously enhancing meningioma based along the left frontal dural convexity. The lesion produces mass effect with midline shift and surrounding edema.

testing by injection of a small-dose cardiac lidocaine through the microcatheter has also be used to identify blood supply to cranial nerves beyond the microcatheter tip. ${ }^{9}$ The development of a temporary cranial nerve deficit after such a provocative test increases the risk of embolization and may warrant catheter repositioning before embolization. After the microcatheter has been properly and safely positioned, embolic material is injected under constant, real-time digital-subtraction fluoroscopy, to allow penetration of the material into the tumor bed, thereby producing devascularization and subsequent necrosis. A variety of embolic materials are available. In general, particulate agents (polyvinyl alcohol particles and acrylic microspheres ${ }^{3,4}$ ) are favored because of their relative ease of use, because the permanence of other agents such as liquid adhesive glue or ethanol is unnecessary in the preoperative setting, and because these liquid agents may easily penetrate small normal arteries below the resolution of fluoroscopic units. Overly vigorous embolization must be avoided because it can cause it can cause reflux of embolic material into normal proximal branches. After the tumor has been embolized, in some instances (usually when the MMA is involved), an occlusive microcoil can be placed into the feeding artery proximal to the tumor bed, permitting easier surgical transection of the artery. After the microcatheter is removed, postembolization angiography is performed to evaluate the angiographic completeness of embolization. Preoperative embolization of the pial meningioma supply, which usually represents secondary parasitized tumoral artery supply, is generally not conducted because the risk of stroke can be greater than the potential benefit of embolization. The timing of subsequent surgery has been debated. Some practitioners have reported that the timing of embolization has no effect on ease of tumor resection, ${ }^{16}$ whereas others have advo- 


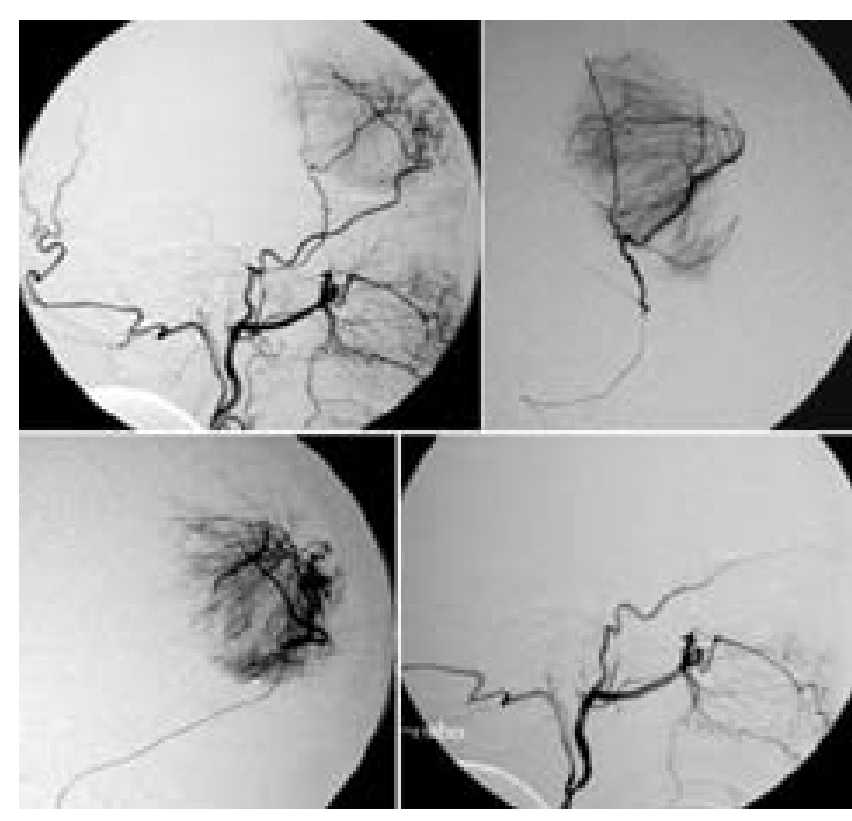

Fig. 2. Upper Left: Preembolization left ECA lateral angiogram, lateral view, demonstrating typical meningioma tumor blush, supplied by enlarged branches of the middle meningeal and superficial temporal arteries. Upper Right: Superselective MMA branch arteriogram, lateral view, obtained immediately before embolization. This branch represents the tumor's primary blood supply. Lower Left: Superselective superficial temporal branch arteriogram, lateral projection, obtained immediately prior to embolization. This artery does not represent primary tumor supply but may be parasitized when the skull becomes invaded by the meningioma. Lower Right: Postembolization left ECA angiogram, lateral view, obtained after particulate embolization of the tumor bed and coil occlusion of the feeding MMA. No residual tumor vascularity is seen. This patient is now prepared to undergo resection of the tumor.

cated a delay of 7 to 10 days following embolization to allow tumor necrosis to occur and to simplify resection. ${ }^{7,13}$

\section{Outcomes and Complications}

In the 1970s anecdotal reports of the efficacy of preoperative meningioma embolization were published; these were single case reports in which tumor resection after embolization was facilitated. ${ }^{11,19}$ Progressively larger patient series were subsequently described,,${ }^{6,8,12,16,17,20}$ providing evidence of angiographic, histological, and surgical efficacy of preoperative embolization. In a more recent report the authors have questioned the benefit of preoperative embolization. ${ }^{5}$ In our view, preoperative embolization of meningiomas is standard treatment in centers offering endovascular therapy.

Palliative embolization has been undertaken as an alternative to definitive resection in patients considered suboptimal candidates for surgery, usually because of general medical condition. ${ }^{6,14}$ No large series to validate this treatment alternative, however, have been performed.

In properly selected cases, the risks of meningioma embolization are small and are related to the experience of the interventional neuroradiologist. ${ }^{9}$ Anecdotal reports of complications, including tumoral ${ }^{22}$ and subarachnoid ${ }^{10}$ hemorrhage, scalp necrosis, ${ }^{1}$ and retinal embolus ${ }^{21}$ have been published. Other potential complications include transient cranial nerve palsies or inadvertent embolization of brain arteries through potential anastomoses of the ECA branches to the ICA or VAs.

\section{CONCLUSIONS}

The practice of preoperative embolization of meningiomas has evolved during the past two decades as a result of accrued experience and technical developments in micocatheters, imaging systems, and embolic materials. This procedure has become the standard of care in the treatment of this common tumor.

\section{References}

1. Adler JR, Upton J, Wallman J, et al: Management and prevention of necrosis of the scalp after embolization and surgery for meningioma. Surg Neurol 25:357-360, 1986

2. Ahuja A, Gibbons KJ, Hopkins LN: Endovascular techniques to treat brain tumors, in Youmans JR (ed): Neurological Surgery, ed 4. Philadelphia: WB Saunders, 1996, Vol 4, pp 2826-2840

3. Beaujeux R, Laurent A, Wassef M, et al: Trisacryl gelatin microspheres for therapeutic embolization, II: preliminary clinical evaluation in tumors and arteriovenous malformations. AJNR 17:541-548, 1996

4. Bendszus M, Klein R, Burger R, et al: Efficacy of trisacryl gelatin microspheres versus polyvinyl alcohol particles in the preoperative embolization of meningiomas. AJNR 21:255-261, 2000

5. Bendszus M, Rao G, Burger R, et al: Is there a benefit of preoperative meningioma embolization? Neurosurgery 47: 1306-1312, 2000

6. Brismar J, Cronqvist S: Therapeutic embolization in the external carotid artery region. Acta Radiol Diagn 19:715-731, 1978

7. Chun JY, McDermott MW, Lamborn KR, et al: Delayed surgical resection reduces intraoperative blood loss for embolized meningiomas. Neurosurgery 50:1231-1237, 2002

8. Gruber A, Killer M, Mazal P, et al: Preoperative embolization of intracranial meningiomas: a 17 -year single center experience. Minim Invasive Neurosurg 43:18-29, 2000

9. Halbach VV, Hieshima GB, Higashida RT, et al: Endovascular therapy of head and neck tumors, in Viñuela F, Halbach VV, Dion JE (eds): Interventional Neuroradiology: Endovascular Therapy of the Central Nervous System. New York: Raven Press, 1992, pp 17-28

10. Hayashi T, Shojima K, Utsunomiya H, et al: Subarachnoid hemorrhage after preoperative embolization of a cystic meningioma. Surg Neurol 27:295-300, 1987

11. Hekster RE, Matricali B, Luyendijk W: Presurgical transfemoral catheter embolization to reduce operative blood loss. Technical note. J Neurosurg 41:396-398, 1974

12. Hieshima GB, Everhart FR, Mehringer CM, et al: Preoperative embolization of meningiomas. Surg Neurol 14:119-127, 1980

13. Kai Y, Hamada J, Morioka M, et al: Appropriate interval between embolization and surgery in patients with meningioma. AJNR 23:139-142, 2002

14. Koike T, Sasaki O, Tanaka R, et al: Long-term results in a case of meningioma treated by embolization alone-case report. Neurol Med Chir 30:173-177, 1990

15. Lasjaunias P, Berenstein A: Surgical Neuroangiography, Vol. 2: Endovascular Treatment of Craniofacial Lesions. Berlin: Springer-Verlag, 1987, Vol 2 
16. Macpherson P: The value of pre-operative embolization of meningioma estimated subjectively and objectively. Neuroradiology 33:334-337, 1991

17. Manelfe C, Lasjaunias P, Ruscalleda J: Preoperative embolization of intracranial meningiomas. AJNR 7:963-972, 1986

18. McDermott MW, Wilson CB: Meningiomas, in Youmans JR (ed): Neurological Surgery, ed 4. Philadelphia: WB Saunders, 1996, Vol 4, pp 2782-2825

19. Pandya SK, Nagpal RD: External carotid embolization-an useful prior adjunct to excision of convexity cerebral meningiomas. Neurology 24:182-184, 1976

20. Teasdale E, Patterson J, McLellan D, et al: Subselective preoperative embolization for meningiomas. A radiological and pathological assessment. J Neurosurg 60:506-511, 1984

21. Turner T, Trobe JD, Deveikis JP: Sequential branch retinal ar- tery occlusions following embolization of an intracranial meningioma. Arch Ophthalmol 120:857-860, 2002

22. Watanabe K, Matsumura K, Matsuda M, et al: [Meningioma with intratumoral and subdural hemorrhage as an immediate complication of therapeutic embolization. Case report.] Neurol Med Chir 26:904-907, 1986 (Jpn)

Manuscript received May 30, 2003.

Accepted in final form June 11, 2003.

Address reprint requests to: Christopher F. Dowd, M.D., The Neurovascular Medical Group, Department of Radiology, San Francisco School of Medicine, University of California, 505 Parnassus Avenue, Room L-352, San Francisco, California 941430628. email: chris.dowd@ radiology.ucsf.edu. 